\title{
Our experience in laryngeal forms of reflux disease
}

\author{
Avramov, T., D. Doskova, D. Doskov \\ ENT Clinic, University Hospital „Tz. Joanna-ISUL“, Sofia
}

\begin{abstract}
:
Introduction: Reflux laryngitis is an inflammation of the rear third of the larynx caused by chronic chemical irritation with hydrochloric acid and digestive enzymes. That usualy happens at night, when due to the supine position of the body is pressed by the abdominal muscles squeeze the stomach as a result of which is amplified refluxTypical symptoms include hoarseness, a sensation of a lump, need to clear a troath and a nonproductive cough (laryngeal paresthesia). Acid reflux is a non necessary symptom in this condition. Approximately one third of all patients is not elevated acidity.

Material and method: We monitored for four years (20092012) 56 patients including 53 with reflux laryngitis and 3 with laryngeal granuloma with typical history of reflux disease manifestations such typical symptoms belching acid did not appear in 14 patients. and was diagnosed GERD (gastroesophageal reflux disease), resulting in gastritis, gastric ulcer, hiatal hernia and failure of the lower esophageal sphincter.

Results: In the first group after 2 month etiological conservative treatment prescribed by a gastroenterologist, had a voice rehabilitation with very good effect. In 42 patients laryngeal paresthesias resolved completely. In the second group (laryngeal granuloma) is not observed significant interference complaints of patients which is necessary to conduct surgery. Two patients due to relapse need reoperation.

Conclusion: The leading therapy is the treatment of gastroesophageal reflux disease from a gastroenterologist and ENT specialist and better collaboration between the two disciplines.
\end{abstract}

\section{List of abriviations:}

GERD-gastroesophageal reflux disease

PPI-proton pump inhibitors

FGS-fibrogastrocopy

Key words: Reflux laryngitis, laryngeal granuloma, gastroesophageal reflux disease, acid reflux

\section{Introduction}

Reflux laryngitis is an inflammation of the rear third of the larynx caused by chronic chemical irritation with hydrochloric acid and digestive enzymes. The main reason for it is gastroesophageal reflux disease (GERD). According to the American Association of Gastroenterology, GERD is a condition that occurs when reflux of gastric contents into the esophagus causes unpleasant esophageal and extraesophageal complications. The latter is expressed with atypical symptoms in other organs-oral cavity, pharynx, larynx and lungs, as most often laryngeal localization. It is expressed in a reflux laryngitis, contact ulcers and granuloma, often in combination with chronic cough reflux (1). They are caused by the reaction of the mucosa of the larynx of the direct action of the reflux content (acid reflux), or the unlocking of reflexes and release mediators of unlocked from acid reflux (acidic reflex). It should be clarified that the granuloma in the larynx (glottis) is subdivided according to the etiological and therapeutic monitoring of contact granuloma, (post) intubation granuloma and granuloma caused by gastroesophageal reflux. The origin is pivotal in planning his treatment. Granulomas are looking as shapely rounded formations with reddish color, located on processus vocalis of the arytenoid cartilage and/or on the sidewall of the rear glottis and usually does not affect the membranous part of the vocal cords. Type of a granuloma can often be distinguished only by history and stroboscopic findings. The lesion may be located unilaterally or bilaterally. Histologically, granulomas consist mainly of fibroblasts, collagen fibers, proliferated capillaries 
and leukocytes. They may be coated or not from epithelium. In initial lesions phonation does not suffers, while the largest suffers. The properties of all layers of the membranous part not changed. In endolaryngostroboscopy not established the existence of segments with reduced or no mobility. These segments can be seen in granuloma caused by GERD with longer duration and size. GERD is one of the most common diseases / according to the American Association of voice every tenth suffered by him / and mainly due to irregular eating a poor diet, stress and obesity. Pathophysiological conditions for chemical irritation are impaired esophageal clearance, dysfunction of the lower esophageal segment, delayed gastric emptying and increased intra-abdominal pressure (2). when due to the supine position of the body is pressed by the abdominal muscles squeeze the stomach as a result of which is amplified reflux. Typical symptoms include hoarseness, a sensation of a lump, need to clear a troath and a nonproductive cough (laryngeal paresthesia) $(4,6)$. Acid reflux is a non necessary symptom in this condition. Acid reflux is not a compulsory symptom of this disease.

\section{Material and method}

We monitored for four years (2009-2012) 56 patients including 53 with reflux laryngitis (I group) and 3 with laryngeal granuloma (II group). Gender distribution in the observation group were 38 men and 18 women. The age of the patients was 25 to 68 years, the average age of the group was 48.29. More than half of them were under the age of 49 years or $57.14 \%$. Patients had a wide variety of professions-IT-specialists, clerks, engineers, teachers, drivers, etc., but this what united them was a history of irregular eating twice as often three times a day. In 30 of the patients or 53,57\% we observed overweight.

Patients used the following research methods:

- history and indirect laryngoscopy

- videolaryngostroboscopy that allowed us registering vibrator activity of glottis

- fibrolaryngoscopy (Olympus).

From history in our patients experience a variety of symptoms-voice disorders (decreased endurance voice), laryngeal paresthesia (sensation of a foreign body in the larynx, burning and less pain) and chronic cough. The latter symptom had in 18 patients or $32.14 \%$.
In a study of all patients seen hyperemia and edema of the mucosa of intercartilaginous part of the larynx, sometimes engaging and posterior third of the true vocal cords.

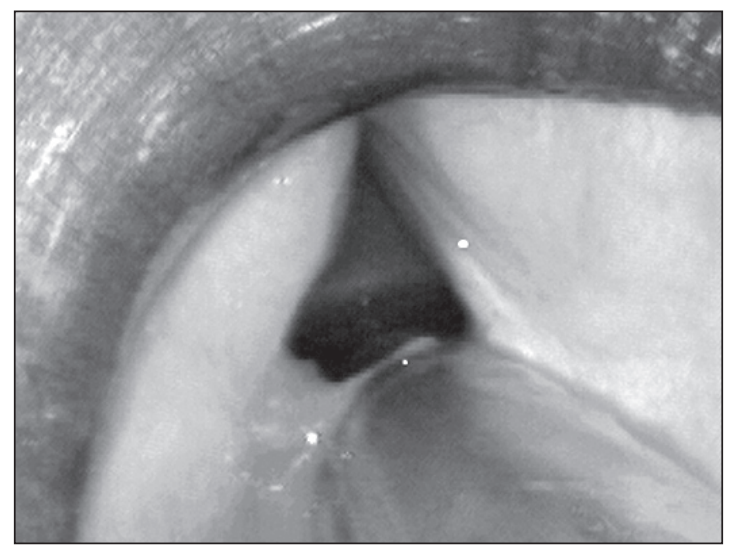

Fig. 1. Laryngeal granuloma

All the patients were consulted with a gastroenterologist in which were established using fibrogastroscopy (FGS), esophageal manometry and $24 \mathrm{~h} \mathrm{pH}$ metry (3) reflux esophagitis and failure of the lower esophageal sphincter in 29 patients or $51.79 \%$, at 6 or $10.71 \%$ hiatal hernia, at 3 or $5.36 \%$ gastritis and 2 or $3.57 \%$ gastric ulcer, but only 39 of them were diagnosed acid reflux (acid belching). We see with $24 \mathrm{pH}$ metry the connection between the day and night reflux episodes and patient complaints.

\section{Results}

Diagnosis of reflux laryngitis in 53 patients (Group I) or 94.64 percent and 3 with laryngeal granuloma (Group II) or 5.36\% put based on history, indirect laryngoscopy (red, swollen and wrinkled mucosa in interarytenoid space and on the arytenoids, etc. posterior laryngitis and the presence of granuloma). From videolaryngostrobscopy received data for more or less pronounced fonator dyskinesia of the glottis.

In the first group after 2 month etiological conservative treatment prescribed by a gastroenterologistantisecretory therapy with PPI (sopral) conducted voice rehabilitation with very good effect (5). In 42 patients laryngeal paresthesia resolved completely. In the second group (with laryngeal granuloma) is not observed significant interference of complaints of patients who had the conduct of surgery. Two patients due to relapse need reoperation. 


\section{Conclusion}

The presence of extraesophageal laryngeal forms of GERD should always think in ineffective treatment of laryngeal symptoms. Primary method of treatment is the voice rehabilitation, which can be supplemented with psychotherapy in some individual cases. In case of granuloma caused by gastroesophageal reflux disease is the leading treatment of the underlying disease, voice rehabilitation and removal of contact granuloma through conventional or $\mathrm{CO}^{2}$ laser surgery is indicated only in individual cases. The granuloma must be connected right at the base while avoiding excessive pressure on the arytenoid cartilage. Injury to the perichondrium of processus vocalis should by all means be avoided, as when is a persistent inflammation of the perichondrium of processus vocalis, it can serve as a nidus for recurrence, even when the granuloma is carefully removed with a $\mathrm{CO}^{2}$ laser or conventional surgery.

The leading therapy is the treatment of gastroesophageal reflux disease from a gastroenterologist and ENT specialist. In our patients, the disappearance of extraesophageal GERD always corresponded with improvement in esophageal GERD, as evidenced by the underlying esophageal manometry and FGS. However note that between the 3rd and 6th month after stopping antisecretory therapy PPI in 16 patients or $28.57 \%$ observed relapse which required re-treatment. All this confirms our observation that the good collaboration between specialties is essential to achieve maximum results.

\section{References:}

1. Vladimirov B., D. Doskov, Sp. Todorov, GERB partnership between gastroenterologist and ENT specialist, Oto Rhino Laryngology International bulletin, 2009, N2, 12-14.

2. KatzkaDA., DiMarino AJ., Pathophysiology of gastroesophageal reflux disease: Les incompetence and esophageal clearance. In: The esophagus, second edition, Castell DO. Little Brown \& Company, Boston, USA, 1995:443-53.

3. Vaezi M,Schroeder PL, Richter JE. Reproducibility of proximal probe $\mathrm{pH}$ parameters 24 -hour ambulatory esophageal $\mathrm{pH}$ monitoring. Am J Gastroenterol. 1997; 92:825-829.

4. Rouev P. et al. Laryngopharyngeal symptoms and gastroesophageal reflux disease. J Voice, 2005, 3: 476-80.

5. Park W, Hicks Dm, Khandwala F, et al. Laryngopharyngeal reflux (LPR): Prospective cohort study evaluating optimal dose of PPI therapy and pre- therapy predictors of response. Laryngoscope, 2005; 115: 1230-1238.

6. Galmiche JP, Zerbib F, Bruley des Varannes S. Review article: respiratory manifestations of gastro-esophageal reflux disease. Aliment Pharmacol Ther.,2, 2008, 6, 449-64

Corresponding author:
Toma Avramov, MD
ENT clinic
UHAT ,Tzaritsa Joanna-ISUL“
toma_avramov@abv.bg
8, Bjalo More str, Sofia, 1508, Bulgaria
tel. +35929432563
Fax +35929432521




\title{
Нашият опит при ларингеални форми на рефлуксната болест
}

Our experience in laryngeal forms of reflux disease

\author{
Аврамов Т., Д. Доскова, Д. Досков \\ УНГ клиника, УМБАЛ „Ц. Йоанна - ИСУЛ“, София \\ Avramov, T., D. Doskova, D. Doskov \\ ENT Clinic, University Hospital „Tz. Joanna - SUL“, Sofia
}

\section{Резюме:}

Въведение: Рефлукс ларингитът е възпаление на задната трета на ларинкса, причинено от хроничното химично дразнене със солна киселина и стомашни ензими. Това става най-вече през нощта, когато поради легналото положение на тялото стомахът се притиска от мускулите на коремната преса в резултат на което се усилва рефлуксьт. Типичните симптоми на заболяването включват: дрезгавост, усещане за чуждо тяло в гърлото, дразнене и нужда от прочистване на гърлото и непродуктивна кашлица (ларингеални парестезии). Киселинният рефлукс не е задължителен симптом при това заболяване. При около една трета от всички пациенти не се установи повишена киселинност.

Материал и метод: Проследяваме за четиригодишен период (2009-2012 г.) 56 пациенти, от които 53 с рефлукс ларингит и 3 с ларингеален гранулом с типичните анамнестични прояви на рефлуксна болест, като типичният симптом кисели уригвания не фигурираше при 14 пациенти. Всички пациети бяха консултирани с гастроентеролог и бе диагностициран ГЕРБ (гастроезофагеална рефлуксна болест), в резултат на гастрит, стомашна язва, хиатална херния, недостатъчност на долния сфинктер на хранопровода.

Резултати: При първата група след 2-месечно етиологично консервативно лечение, назначено от гастроентеролог, проведохме гласова рехабилитация с много добър ефект. При 42 пациенти ларингеалните парестезии отзвучаха напълно. При втората група (с ларингеален гранулом) не наблюдавахме значимо повлияване на оплакванията на болните, което наложи провеждането на оперативно лечение. При двама от пациентите поради рецидив се наложи реоперация.

Заключение: Водещото лечение е третирането на гастроезофагиална рефлуксна болест от гастроентеролог и ларинголог, както и добрата колаборация между двете специалности.

\section{Абривиетура:}

ГЕРБ - гастроезофагиална рефлуксна болест

ИПП - инхибитори на протонната помпа

ФГС - фиброгастроскопия

\section{Въведение}

Рефлукс ларингитьт е възпаление на задната трета на ларинкса, причинено от хроничното химично дразнене със солна киселина и стомашни ензими. Основна причина за него е гастроезофагеалната рефлуксна болест (ГЕРБ). Според Американската асоциация по гастроентерология ГЕРБ е състояние, което се проявява при рефлукс на стомашно съдържимо в хранопровода и предизвиква неприятни езофагеални и екстраезофагеални усложнения. Последните се изразяват с атипични симптоми от страна на други органи - устна кухина, фаринкс, ларинкс и бели дробове, като най-честа е ларингеалната локализация. Тя се изразява в рефлукс ларингит, контактни язви и грануломи, често в комбинация с хронична рефлуксна кашлица (1). Те се дължат на реакцията на лигавицата на ларинкса на директното действие на рефлуксното съдържимо (киселинния рефлукс) или на отключването на рефлекси и отделянето на медитори, отключени от киселинния рефлукс (киселинен рефлекс). Трябва да се уточни, че грануломът в областта на ларинкса (глотиса) се подразделя според етиологичните и терапевтични наблюдения на контактен гранулом, /пост/интубационен гранулом и гранулом, причинен от гастроезофагеален рефлукс. Произходът има определящо значение при планиране на лечението му. Грануломите се оглеждат като добре оформени окръглени образувания с червеникав цвят, разположени върху процесус вокалис на аритеноидния хру- 
Ключови думи: рефлукс ларингит, ларингеален гранулом, извън езофагеални форми на ГЕРБ, ларингеални парестезии.

\begin{abstract}
:
Introduction: Reflux laryngitis is an inflammation of the rear third of the larynx caused by chronic chemical irritation with hydrochloric acid and digestive enzymes.when due to the supine position of the body is pressed by the abdominal muscles squeeze the stomach as a result of which is amplified reflux.Approximately one third of all patients is not elevated acidity.

Material and method: We monitored for four years (20092012) 56 patients including 53 with reflux laryngitis and 3 with laryngeal granuloma with typical history of reflux disease manifestations such typical symptoms belching acid did not appear in 14 patients. and was diagnosed GERD (gastroesophageal reflux disease), resulting in gastritis, gastric ulcer, hiatal hernia and failure of the lower esophageal sphincter.

Results: In the first group after 2 month etiological conservative treatment prescribed by a gastroenterologist, had a voice rehabilitation with very good effect. In 42 patients laryngeal paresthesias resolved completely. In the second group (laryngeal granuloma) is not observed significant interference complaints of patients which is necessary to conduct surgery. Two patients due to relapse need reoperation.

Conclusion: The leading therapy is the treatment of gastroesophageal reflux disease from a gastroenterologist and ENT specialist and better collaboration between the two disciplines.
\end{abstract}

\section{List of abriviations:}

GERD-gastroesophageal reflux disease

PPI-proton pump inhibitors

FGS-fibrogastrocopy

Key words: Reflux laryngitis, laryngeal granuloma, gastroesophageal reflux disease, acid reflux щял и/или върху страничната стена на задния глотис и обикновено не се засяга мембранозната част на гласната връзка. Типът на гранулома често може да бъде разграничен само по анамнезата и стробоскопската находка. Лезията може да бъде разположена едностранно или двустранно. Хистологично грануломите се състоят основно от фибробласти, колагенови влакна, пролиферирали капиляри и левкоцити. Те могат да бъдат покрити или не от епител. При начални лезии затварянето на гласната цепка при фонация не страда, докато при големите се нарушава. Свойствата на всички слоеве на мембранозната част не са променени. При ендоларингостробоскопия не се установява наличието на сегменти с намалена или липсваща подвижност. Такива сегменти могат да се наблюдават при гранулом вследствие на ГЕРБ с по-голяма давност и големина.

ГЕРБ е сред най-често срещаните заболявания (според Американската асоциация на гласа всеки десети страда от него) и се дължи най-вече на нередовно хранене с некачествена храна, стреса и затлъстяването. Патофизиологични предпоставки за химичното дразнене са нарушения в езофагеалния клирънс, дисфункция на долния езофагеален сегмент, забавеното стомашно изпразване и повишеното интраабдоминално налягане (2). Това става най-вече през нощта, когато поради легналото положение на тялото стомахът се притиска от мускулите на коремната преса, в резултат на което се усилва рефлуксът. Типичните симптоми на заболяването включват: дрезгавост, усещане за чуждо тяло в гърлото, дразнене и нужда от прочистване на гърлото и непродуктивна кашлица (ларингеални парестезии) $(4,6)$. Киселиннят рефлукс не е задължителен симптом при това заболяване.

\section{Материал и метод}

Проследяваме за четиригодишен период (20092012 г.) 56 пациенти $(\mathrm{n}=56)$, от които 53 с рефлукс ларингит (I група) и 3 с ларингеален гранулом (II група). Според пола разпределението в наблюдаваната група беше 38 мъже и 18 жени. Възрастта на пациентите беше от 25 до 68 години, като средната възраст на групата е 48,29 г. Повече от половината от тях бяха на възраст под 49 години, или 57,14\%. Пациентите имаха най-разнообразни професии - IT-специалисти, чиновници, инженери, преподаватели, шофьори и др., но това, което ги обединяваше 
от анамнезата, беше нередовното хранене, два пъти по-рядко три пъти на ден. При 30 от пациентите, или 53,57\% наблюдавахме наднормено тегло.

При пациентите използвахме следните методи за изследване:

- анамнеза и индиректна ларингоскопия

- видеоларингостробоскопия, която ни позволяваше регистрирането на вибраторната активност на глотиса

- фиброларингоскопия (Olympus).

От анамнезата при нашите пациенти наблюдавахме разнообразни оплаквания - гласови смущения (намалена гласова издръжливост), ларингеални парестезии (усещане за чуждо тяло в областта на ларинкса, парене и по-рядко болка) и хронична кашлица. Последният симптом имахме при 18 от пациентите, или 32,14\%.

При изследване на всички пациенти наблюдавахме хиперемия и оток на лигавицата на интеркартилагинерната част на ларинкса, понякога ангажираща и задната трета на истинските гласни връзки.

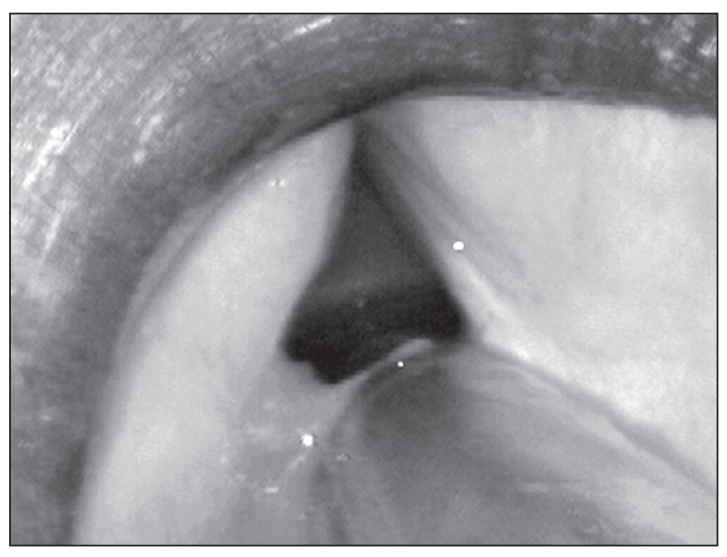

Фиг. 1. Ларингеален гранулом

Всички пациенти бяха консултирани с гастроентеролог, при което бяха установени с помощта на фиброезофагогастроскопия (ФГС), езофагеална манометрия и 24 ч. $\mathrm{pH}$ метрия (3) - рефлукс езофагит и недостатьчност на долния езофагеален сфинктер при 29 от пациентите, или 51,79\%, при 6 , или $10,71 \%$ - хиатална херния, при 3 , или $5,36 \%$ - гастрит и при 2 , или $3,57 \%$ - стомашна язва, но само при 39 от тях се диагностицира киселинен рефлукс (кисели уригвания). От проведената 24 ч. $\mathrm{pH}$ метрия се видя връзката между дневните и нощни рефлуксни епизоди и оплакванията на пациентите.

\section{Резултати}

Диагнозата рефлукс ларингит при 53 от пациентите (I група), или 94,64\%, и 3 с ларингеален гранулом (II група), или 5,36\%, поставихме въ3 основа на анамнезата, индиректната ларингоскопия (зачервена, оточна и нагъната лигавица в интераритеноидното пространство и върху аритеноидите, т.нар. заден ларингит, както и наличието на гранулом). От видеоларингостробскопията получихме данни за по-силно или по-слабо изразена фонаторна дискинезия на глотиса.

При първата група след 2-месечно етиологично консервативно лечение, назначено от гастроентеролог - антисекреторна терапия с ИПП (Сопрал), проведохме гласова рехабилитация с много добър ефект (5). При 42 пациенти ларингеалните парестезии отзвучаха напълно. При втората група (с ларингеален гранулом) не наблюдавахме значимо повлияване на оплакванията на болните, което наложи провеждането на оперативно лечение. При двама от пациентите поради рецидив се наложи реоперация.

Заключение: За наличие на екстраезофагеални ларингеални форми на ГЕРБ винаги трябва да се мисли при неефективно лечение на ларингеалната симптоматика. Основният начин на лечение е гласовата рехабилитация, която може да се допълни с психотерапия в отделни случаи. При гранулома, причинен от гастроезофагеален рефлукс, водещо е лечението на основното заболяване, гласовата рехабилитация, а отстраняването на контактния гранулом посредством конвенционална или $\mathrm{CO}_{2}$ лазерна хирургия е показано само в отделни случаи. Грануломът трябва да се захване точно в основата, като се избягва прекален натиск върху аритеноидния хрущял. Нараняването на перихондриума на процесус вокалис трябва всячески да се избягва, тъй като, когато е налице персистиращо възпаление на перихондриума на процесус вокалис, то може да послужи като огнище за рецидив, дори и когато грануломът е внимателно отстранен с конвенционална или $\mathrm{CO}_{2}$ лазерна хирургия.

Водещото лечение е третирането на гастроезофагеалната рефлуксна болест от гастроентеролог и ларинголог. При нашите пациенти изчезването на екстраезофагеалните форми на ГЕРБ кореспондираше винаги и с подобрение на езофагеалните форми на ГЕРБ, което се доказва от 
извършените ФГС и езофагеална манометрия. Трябва обаче да отбележим, че между 3-я и 6-я месец след спиране на антисекреторната терапия с ИПП при 16 от пациентите, или 28,57\%, наблюдавахме рецидив, което наложи повто- рен курс на лечение. Всичко това потвърждава нашето наблюдение, че добрата колаборация между специалностите е от първостепенна важност за постигане на максимални резултати.

\section{References:}

1. Vladimirov B., D. Doskov, Sp. Todorov, GERB partnership between gastroenterologist and ENT specialist, Oto Rhino Laryngology International bulletin, 2009, N2, 12-14.

2. KatzkaDA., DiMarino AJ., Pathophysiology of gastroesophageal reflux disease: Les incompetence and esophageal clearance. In: The esophagus, second edition, Castell DO. Little Brown \& Company, Boston, USA, 1995:443-53.

3. Vaezi M,Schroeder PL, Richter JE. Reproducibility of proximal probe $\mathrm{pH}$ parameters 24 -hour ambulatory esophageal $\mathrm{pH}$ monitoring. Am J Gastroenterol. 1997; 92:825-829.

4. Rouev P. et al. Laryngopharyngeal symptoms and gastroesophageal reflux disease. J Voice, 2005, 3: 476-80.

5. Park W, Hicks Dm, Khandwala F, et al. Laryngopharyngeal reflux (LPR): Prospective cohort study evaluating optimal dose of PPI therapy and pre- therapy predictors of response. Laryngoscope, 2005; 115: 1230-1238.

6. Galmiche JP, Zerbib F, Bruley des Varannes S. Review article: respiratory manifestations of gastro-esophageal reflux disease. Aliment Pharmacol Ther.,2, 2008, 6, 449-64.

Corresponding author:

Toma Avramov, $M D$

$$
\text { ENT clinic }
$$

UHAT ,Tzaritsa Joanna-ISUL“

toma_avramov@abv.bg

8, Bjalo More str, Sofia, 1508, Bulgaria

tel. +35929432563

Fax +35929432521 